$$
\begin{aligned}
& \text { - Edson Duarte Moreira Junior } \\
& \text { - Dale Glasser } \\
& \text { - Dianilson Barbosa dos Santos } \\
& \text { - Clive Gingell }
\end{aligned}
$$

CONTEXT AND OBJECTIVE: Relatively little is known about the usual frequency of sexual activity and how older individuals cope with sexual problems. The objective was to study sexual activity, prevalence of sexual problems and related help-seeking behaviors among middle-aged and older men and women in Brazil.

DESIGN AND SETTING: Population survey, by Fundação Oswaldo Cruz.

METHODS: Interviews were held with 1,199 Brazilians aged $40-80$ years (471 men and 728 women). The standardized questionnaire investigated demographics, general health, sexual behavior, attitudes and beliefs.

RESULTS: Overall, $92.6 \%$ of men and $58.3 \%$ of women had had sexual intercourse during the preceding year. More than half of the men and women had done so more than once a week. Early ejaculation $(30.3 \%)$ was the commonest male sexual problem, followed by inability to reach orgasm $(14.0 \%)$, erectile difficulties $(13.1 \%)$ and lack of sexual interest $(11.2 \%)$. For women, the commonest sexual problems were lubrication difficulties $(23.4 \%)$ and lack of sexual interest $(22.7 \%)$. Depression was a significant correlate of sexual problems, for men and women. More women than men had sought help for sexual problem(s) from a healthcare professional.

CONCLUSIONS: The findings highlight the importance of encouraging greater use of available healthcare services, including consultation with a medical doctor regarding sexual health. This should not only enable men and women to maintain satisfactory sexual function well into their later years, but may also result in overall improvement in the quality of healthcare.

KEY WORDS: Epidemiology. Health surveys. Erectile dysfunction. Prevalence. Sex disorders.

\title{
Prevalence of sexual problems and related help-seeking behaviors among mature adults in Brazil: data from the Global Study of Sexual Attitudes and Behaviors
}

\author{
Centro de Pesquisa Gonçalo Moniz, Fundação Oswaldo Cruz, and \\ scientific directorate of Hospital São Rafael, Salvador, Bahia, Brazil
}

INTRLDUCTION

The development of several convenient and effective oral treatments for male erectile dysfunction has contributed to the increasing level of interest in the sexual functioning of middle-aged and older adults that has been seen in recent years. Over the last 10 years or so, a large number of studies have investigated the prevalence of sexual problems among middle-aged and elderly people. These studies have tended to focus mainly on the populations of individual countries in Europe ${ }^{1-5}$ the United States of America (USA), ${ }^{6-10}$ and Central and South America. ${ }^{11-15}$ The prevalence and correlates of the male sexual disorders of erectile dysfunction and early ejaculation have been studied most extensively, while fewer investigations have looked specifically at female sexual problems. ${ }^{16,17}$ Furthermore, relatively little has been reported about the usual frequency of sexual activity and the value and significance of sexual relationships for older individuals, although the few published studies in this area have concluded that sexual interest and activity persist well into older age. ${ }^{18-20}$

The published literature on the prevalence and correlates of sexual disorders comprises studies conducted in developed and developing countries that have employed a wide variety of study designs and definitions. This makes it difficult to conduct cross-national comparisons in a scientifically valid manner. Moreover, there are currently no studies that allow a comparison of sexual behavior or helpseeking patterns for sexual problems across different countries.

The Global Study of Sexual Attitudes and Behaviors (GSSAB) was a population survey of 27,500 men and women aged 40 to 80 years in 29 countries representing many world regions. ${ }^{21,23}$ Brazil was one of the countries within this study.
口BJECTIVE

Here, our goal is to report data on sexual activity, the prevalence of sexual problems and related help-seeking behaviors among men and women in the Brazilian cohort of the Global Study of Sexual Attitudes and Behaviors.

METHDDS

\section{TYPE DF BTUDY}

Population survey.

\section{SETTINE}

A computer-assisted telephone interview survey, using random-digit dialing as the sampling design, was carried out in Brazil during 2001 and 2002 (participants were sampled from the five largest cities in Brazil, namely, São Paulo, Rio de Janeiro, Salvador, Belo Horizonte, and Brasília). Respondents were randomly selected by asking for the man or woman in the household aged between 40 and 80 years of age (participants were interviewed by interviewers of the same gender).

A structured questionnaire requested information concerning general health, demographics, relationships, and sexual behavior, attitudes and beliefs. The subjects were asked if they had engaged in sexual intercourse during the previous 12 months, and the presence of sexual dysfunction was assessed by means of two sequential questions. The respondents were first asked whether they had experienced one or more of the sexual problems listed in Tables $2 \mathrm{a}$ and $2 \mathrm{~b}$ for $\mathrm{a}$ period of at least two months during the previous year, and those who answered 'Yes' were then asked whether they had experienced the problem 'occasionally', 'sometimes' or 'frequently'.

Logistic regression was used to investigate potential factors associated with selected sexual dysfunction. In these analyses, the presence of a sexual dysfunction was coded only for those respondents who reported experiencing 
the problem frequently or periodically, while those who indicated that they experienced the problem only occasionally were recorded as indicating no sexual dysfunction.

The subjects who reported that they had experienced a sexual problem were asked whether they had sought help from a number of possible sources. The options included: "Talked to partner", "Talked to a medical doctor (other than a psychiatrist)", "Looked for information anonymously (in books/ magazines or on the internet)", "Talked to family member or friend", "Taken prescription drugs/devices or talked to pharmacist", "Talked to psychiatrist or psychologist or marriage counselor", "Talked to a cleric or religious adviser", "Called a telephone help line" and "Other - please specify". Respondents could indicate that they had sought help from more than one source.

The subjects with sexual problems who had not consulted a physician were asked why

Table 1. Selected characteristics of the study population, Brazil, 2001-2002 (percentage; age-standardized prevalences)

\begin{tabular}{|c|c|c|}
\hline & $\begin{array}{c}\text { Men } \\
(n=471)\end{array}$ & $\begin{array}{c}\text { Women } \\
(\mathrm{n}=\mathbf{7 2 8})\end{array}$ \\
\hline \multicolumn{3}{|l|}{ Age group (years) } \\
\hline $40-49$ & 29.9 & 30.8 \\
\hline $50-59$ & 32.1 & 29.8 \\
\hline $60-69$ & 22.5 & 21.7 \\
\hline $70-80$ & 15.5 & 17.7 \\
\hline \multicolumn{3}{|l|}{ Relationship status } \\
\hline Married or ongoing partnership & 82.6 & 54.3 \\
\hline Divorced/separated without sex partner & 8.9 & 13.2 \\
\hline Widowed without sex partner & 4.7 & 22.0 \\
\hline Single without sex partner & 3.8 & 10.6 \\
\hline Urban residential setting & 93.8 & 97.4 \\
\hline \multicolumn{3}{|l|}{ Education } \\
\hline Primary school or less & 36.3 & 47.1 \\
\hline Secondary/high school & 36.5 & 35.0 \\
\hline At least some college & 27.2 & 17.9 \\
\hline \multicolumn{3}{|l|}{ Household income } \\
\hline Low & 12.4 & 23.8 \\
\hline Medium & 78.5 & 70.8 \\
\hline High & 9.2 & 5.4 \\
\hline \multicolumn{3}{|l|}{ Current employment status } \\
\hline Employed & 57.3 & 35.0 \\
\hline Unemployed & 4.9 & 3.2 \\
\hline Retired & 37.8 & 22.9 \\
\hline Homemaker & 0 & 38.9 \\
\hline \multicolumn{3}{|l|}{ Religion } \\
\hline Christian/Jewish & 89.4 & 88.7 \\
\hline Atheist & 3.3 & 1.3 \\
\hline Other, specified & 7.3 & 10.0 \\
\hline Good to excellent general health* & 66.5 & 54.1 \\
\hline Intercourse in the last 12 months & 92.6 & 58.3 \\
\hline Intercourse more than once a week & 65.6 & 57.2 \\
\hline
\end{tabular}

*Self-reported "good" or "excellent" general health (versus "fair" or "poor").

they had not done so, and offered a list of 14 possible reasons (from which they were to check all that applied). The reasons included attitudes and beliefs regarding the sexual problem and the patient-doctor relationship. All respondents (irrespective of whether they reported any sexual problems) were also asked "During a routine office visit or consultation in the past 3 years, has your physician asked you about possible sexual difficulties without you bringing it up first?" (Yes/No) and "Do you think a doctor should routinely ask patients about their sexual function?" (Yes/No). The categorization of household income as "low", "medium" or "high" was based on the distribution of income in Brazil according to the criteria of the Instituto Brasileiro de Geografia e Estatística. ${ }^{24}$

The prevalence of a specific characteristic was calculated by dividing the number of cases by the corresponding population. The denominator for the calculation of the prevalence of sexual problem was the number of sexually active people (i.e. at least one episode of intercourse during the previous 12 months). The prevalence estimates were age-standardized using the age distribution of the population of Brazil (by gender when appropriate), and are given with their confidence intervals. ${ }^{25}$

RESULTS

\section{CHARACTERIBTICB OF BTUDY POPULATION}

Overall, 8,637 individuals were contacted, 2,127 of whom were not eligible to participate (outside of the age range). Of the 6,510 eligible individuals, 5,088 refused to participate when the survey topic was introduced, while 223 interrupted the interview. A total of 1,199 individuals ( 471 men and 728 women) completed the survey, thus giving a response rate of $18.4 \%$. Table 1 presents data on selected characteristics of the study sample, standardized for the age distribution of the population of Brazil in the year 2000. A greater proportion of men $(82.6 \%)$ than women $(54.3 \%)$ were married or in an ongoing partnership (Table 1). More than half of the men $(57.3 \%)$ and about one-third of the women $(35.0 \%)$ were employed and $66.5 \%$ of men and $54.1 \%$ of women reported that they were in good or excellent general health.

Almost all of the men $(92.6 \%)$ and more than half of the women $(58.3 \%)$ said that they had had sexual intercourse during the 12 months preceding the interview, and $58.4 \%$ of men and $26.1 \%$ of women engaged in sexual intercourse more than once a week. 


\section{PREVALENCE QF}

\section{BEXUAL PROBLEMB}

Early ejaculation was by far the most common male sexual problem, and was reported by almost one-third (30.3\%) of the sexually active men (most of who said that they experienced this problem periodically or frequently) (Table 2). An inability to reach orgasm, erectile difficulties and a lack of sexual interest were each experienced by approximately 11 to $14 \%$ of sexually active men, while a lack of pleasure in sex $(7.8 \%)$ and pain during sexual intercourse $(4.5 \%)$ were much less common.

Lubrication difficulties (23.4\%) were the most common sexual problem reported by sexually active women in Brazil, closely followed by lack of sexual interest $(22.7 \%)$ and an inability to reach orgasm $(22.0 \%)$, while a lack of pleasure in sex and pain during sexual intercourse were experienced by $20.3 \%$ and $18.0 \%$ of sexually active women, respectively (Table 2). The majority of the women who reported each of these problems said that they experienced it frequently or periodically.

Physical, health, demographic and socioeconomic factors associated with three selected sexual dysfunctions in men and women are summarized in Table 3 (odds ratios from logistic regression). Older age (age 60 to 80 years compared with the referent age of 40 to 49 years) was a significant correlate of lubrication difficulties in women (odds ratio 2.10; $\mathrm{p}<0.05$ ). Of the various factors investigated and listed in Table 3, three medical conditions were significantly associated with an increased likelihood of one or more types of male sexual dysfunction (i.e. a sexual problem that was experienced periodically or frequently), while only one of the factors was a significant correlate of sexual dysfunction in women. A diagnosis of depression was a significant correlate of erectile difficulties (odds ratio 3.02; $\mathrm{p}<0.01$ ), and early ejaculation (odds ratio 1.98; $\mathrm{p}<0.05$ ) among men, and of a lack of sexual interest in both men (odds ratio 4.37; $\mathrm{p}<0.001$ ) and women (odds ratio 1.68; $\mathrm{p}<0.05$ ). Diagnoses of hypertension and prostate disease were significant correlates of early ejaculation (odds ratio 1.95; $\mathrm{p}<0.05$ ) and a lack of sexual interest (odds ratio 2.77; $\mathrm{p}<0.05$ ), respectively.

\section{HELP-gEEKINI BEHAVIDR}

The prevalence of selected help-seeking behavior for sexual problems in Brazil is summarized in Table 4. Of the respondents who were sexually active and reported experiencing at least one sexual problem,
$41.3 \%$ of men and $29.7 \%$ of women had not sought any help or advice (i.e. no action taken). Patterns of help-seeking behavior showed some differences between men and women in Brazil. More than twice as many women $(44.0 \%)$ as men $(21.2 \%)$ reported talking to a medical doctor about their sexual problem(s). However, overall, about half of the women $(53.1 \%)$ and almost three-quarters of the men $(72.1 \%)$ had sought no help from a health professional. Talking to their partner was a similarly popular course of action among men and women $(42.3 \%$ and $41.4 \%$, respectively), while women were more likely than men to talk to a friend or family member $(25.3 \%$ versus $10.6 \%)$ and to seek information from an anonymous source such as books and magazines, telephone help-lines or the internet (18.3\% versus $12.0 \%)$. Few men $(3.8 \%)$ and women $(6.2 \%)$ reported seeking help from a member of the clergy or other religious adviser.

\section{FACTORB ABSOCIATED WITH BEEKINE MEDICAL HELP FOR gEXUAL PRDBLEME}

A number of physical, socioeconomic and attitudinal factors that might be associated with seeking medical help for sexual problems were investigated using logistic regression and the results (odds ratios) for men and women in Brazil are summarized in Table 5. Women with a high or medium household income were more likely than those with a low income to seek medical help for sexual problems (odds ratio 2.18; $\mathrm{p}<0.05$ ), but income was not a significant factor for men. None of the male sexual

Table 2. Age-standardized prevalence of sexual problems by gender in Brazil, according to severity, 2001-2002 (percentage and 95\% confidence interval)

\begin{tabular}{|c|c|c|}
\hline & $\operatorname{Men}(n=471)$ & Women $(n=728)$ \\
\hline Early ejaculation & $30.3(26.0,34.8)$ & \\
\hline Occasional & $4.6(2.8,7.0)$ & \\
\hline Periodic & $14.4(11.3,18.1)$ & \\
\hline Frequent & $11.2(8.4,14.6)$ & \\
\hline Lubrication difficulties & & $23.4(19.4,27.7)$ \\
\hline Occasional & & $3.5(2.0,5.8)$ \\
\hline Periodic & & $13.9(10.8,17.6)$ \\
\hline Frequent & & $5.9(3.9,8.6)$ \\
\hline Erectile difficulties & $13.1(10.1,16.6)$ & \\
\hline Occasional & $4.1(2.5,6.4)$ & \\
\hline Periodic & $6.2(4.1,8.9)$ & \\
\hline Frequent & $2.8(1.4,4.8)$ & \\
\hline Lack of sexual interest & $11.2(8.4,14.6)$ & $22.7(18.8,27.0)$ \\
\hline Occasional & $2.8(1.4,4.8)$ & $3.8(2.2,6.1)$ \\
\hline Periodic & $6.0(3.9,8.6)$ & $11.8(8.9,15.3)$ \\
\hline Frequent & $2.5(1.3,4.5)$ & $7.1(4.8,10.0)$ \\
\hline Inability to reach orgasm & $14.0(10.9,17.6)$ & $22.0(18.1,26.2)$ \\
\hline Occasional & $4.4(2.6,6.7)$ & $4.5(2.6,6.7)$ \\
\hline Periodic & $7.1(4.9,9.9)$ & $13.0(9.9,16.6)$ \\
\hline Frequent & $2.5(1.3,4.5)$ & $4.5(2.6,6.7)$ \\
\hline Sex not pleasurable & $7.8(5.5,10.7)$ & $20.3(16.6,24.5)$ \\
\hline Occasional & $3.0(1.6,5.0)$ & $4.0(2.4,6.4)$ \\
\hline Periodic & $3.2(1.8,5.3)$ & $10.4(7.7,13.7)$ \\
\hline Frequent & $1.6(0.6,3.3)$ & $5.9(3.9,8.6)$ \\
\hline Pain during sex & $4.6(2.8,7.0)$ & $18.0(14.4,22.0)$ \\
\hline Occasional & $1.4(0.5,3.0)$ & $2.1(1.0,4.0)$ \\
\hline Periodic & $1.8(0.8,3.6)$ & $10.6(7.9,14.0)$ \\
\hline Frequent & $1.4(0.5,3.0)$ & $5.2(3.3,7.8)$ \\
\hline
\end{tabular}

Note: based on reports from sexually active respondents (those who had had intercourse within the past year). Percentage in the first row of each panel indicates the overall prevalence of the sexual problem, defined as experiencing the problem for a period of two months or more. The difference between the overall prevalence and the sum of the three levels of severity of each sexual problem indicates the proportion that failed to specify the level of severity. All prevalence estimates are adjusted according to the age distribution of the total of sexually active men and women in this sample from Brazil. 
Table 3. Factors associated with sexual dysfunction by gender, Brazil, 2001-2002

\begin{tabular}{|c|c|c|c|c|c|c|}
\hline & \multicolumn{3}{|c|}{ Men } & \multicolumn{3}{|c|}{ Women } \\
\hline & $\begin{array}{c}\text { Early } \\
\text { ejaculation }\end{array}$ & $\begin{array}{c}\text { Lack of } \\
\text { sexual interest }\end{array}$ & $\begin{array}{c}\text { Erectile } \\
\text { difficulties }\end{array}$ & $\begin{array}{l}\text { Inability to } \\
\text { reach orgasm }\end{array}$ & $\begin{array}{c}\text { Lack of } \\
\text { sexual interest }\end{array}$ & $\begin{array}{l}\text { Lubrication } \\
\text { difficulties }\end{array}$ \\
\hline \multicolumn{7}{|l|}{ Age } \\
\hline $40-49$ & Referent & Referent & Referent & Referent & Referent & Referent \\
\hline $50-59$ & $0.70(0.40,1.24)$ & $1.10(0.40,2.98)$ & $0.67(0.26,1.73)$ & $0.69(0.40,1.19)$ & $0.68(0.40,1.18)$ & $0.92(0.54,1.58)$ \\
\hline $60-80$ & $0.60(0.33,1.09)$ & $1.56(0.59,4.14)$ & $1.04(0.42,2.55)$ & $0.44(0.24,1.13)$ & $0.73(0.42,1.27)$ & $2.10(1.13,3.91)^{*}$ \\
\hline \multicolumn{7}{|l|}{ Level of physical activity } \\
\hline average and above & Referent & Referent & Referent & Referent & Referent & Referent \\
\hline lower than average & $1.20(0.66,2.16)$ & $0.77(0.29,2.07)$ & $0.90(0.37,2.23)$ & $0.85(0.46,1.57)$ & $1.49(0.88,2.50)$ & $0.99(0.54,1.80)$ \\
\hline \multicolumn{7}{|l|}{ Smoking } \\
\hline never & Referent & Referent & Referent & Referent & Referent & Referent \\
\hline currently + smoked before & $1.13(0.70,1.84)$ & $1.21(0.57,2.59)$ & $1.37(0.65,2.88)$ & $0.72(0.45,1.14)$ & $0.84(0.54,1.31)$ & $0.71(0.45,1.14)$ \\
\hline \multicolumn{7}{|l|}{ Education } \\
\hline primary school or less & Referent & Referent & Referent & Referent & Referent & Referent \\
\hline secondary/some college & $0.70(0.43,1.12)$ & $0.83(0.40,1.76)$ & $0.74(0.37,1.74)$ & $1.06(0.65,1.72)$ & $1.44(0.90,2.31)$ & $1.11(0.68,1.82)$ \\
\hline \multicolumn{7}{|l|}{ Household income } \\
\hline low & Referent & Referent & Referent & Referent & Referent & Referent \\
\hline medium and high & $0.69(0.37,1.32)$ & $0.78(0.29,2.10)$ & $1.34(0.47,3.84)$ & $0.88(0.51,1.52)$ & $0.81(0.48,1.35)$ & $1.28(0.71,2.32)$ \\
\hline \multicolumn{7}{|l|}{ Medical Conditions } \\
\hline Depression diagnosed & $1.98(1.04,3.78)^{*}$ & $4.37(1.93,9.86)^{\ddagger}$ & $3.02(1.35,6.73)^{\dagger}$ & $1.50(0.91,2.46)$ & $1.68(1.06,2.67)^{*}$ & $1.51(0.92,2.50)$ \\
\hline Hypertension diagnosed & $1.95(1.17,3.25)^{*}$ & $0.52(0.21,1.26)$ & $1.81(0.86,3.79)$ & $1.55(0.94,2.57)$ & $1.00(0.61,1.63)$ & $0.90(0.53,1.53)$ \\
\hline Diabetes diagnosed & $1.13(0.50,2.60)$ & $1.53(0.50,4.73)$ & $2.15(0.81,5.65)$ & $1.23(0.55,2.75)$ & $1.00(0.45,2.19)$ & $1.00(0.42,2.46)$ \\
\hline Heart disease & $0.98(0.51,1.90)$ & $1.79(0.72,4.46)$ & $1.66(0.72,3.81)$ & $0.98(0.49,1.99)$ & $1.73(0.94,3.21)$ & $1.37(0.67,2.81)$ \\
\hline Prostate disease & $1.58(0.74,3.37)$ & $2.77(1.10,6.92)^{*}$ & $1.79(0.68,4.70)$ & & & \\
\hline
\end{tabular}

Note: In the odds ratios from logistic regression (and $95 \%$ confidence intervals) of these analyses, the presence of a sexual dysfunction included only those respondents who reported having experienced the problem "sometimes" or "frequently" (i.e. those who indicated "occasionally" were recorded as indicating no sexual problem). Based on reports from sexually active subjects. ${ }^{*} p<0.05 ;{ }^{t} p<0.01 ;{ }^{\ddagger} p<0.001$.

Table 4. Prevalence of selected help seeking behaviors for sexual problems by gender, Brazil, 2001-2002

\begin{tabular}{|c|c|}
\hline & $\%(95 \%$ confidence interval) \\
\hline \multicolumn{2}{|l|}{ Men } \\
\hline Talked to partner & $42.3(35.5,49.3)$ \\
\hline Talked to medical doctor & $21.2(15.8,27.3)$ \\
\hline Taken drugs/used devices or talked to pharmacist & $18.8(13.7,24.7)$ \\
\hline Looked for information anonymously (in books/magazines or via telephone help-line/internet) & $12.0(7.9,17.2)$ \\
\hline Talked to family member/friend & $10.6(6.7,15.6)$ \\
\hline Talked to psychiatrist, psychologist or marriage counselor & $6.7(3.7,11.0)$ \\
\hline Talked to a cleric or religious adviser & $3.8(1.7,7.4)$ \\
\hline Sought no help from a health professional & $72.1(65.5,78.1)$ \\
\hline No action taken & $41.3(34.6,48.4)$ \\
\hline \multicolumn{2}{|l|}{ Women } \\
\hline Talked to medical doctor & $44.0(38.0,50.1)$ \\
\hline Talked to partner & $41.4(35.5,47.5)$ \\
\hline Talked to family member/friend & $25.3(20.2,30.9)$ \\
\hline Taken drugs/used devices or talked to pharmacist & $22.7(17.9,28.1)$ \\
\hline Looked for information anonymously (in books/magazines or via telephone help-line/internet) & $18.3(13.9,23.4)$ \\
\hline Talked to psychiatrist, psychologist or marriage counselor & $8.4(5.4,12.4)$ \\
\hline Talked to a cleric or religious adviser & $6.2(3.7,9.8)$ \\
\hline Sought no help from a health professional & $53.1(47.0,59.2)$ \\
\hline No action taken & $29.7(24.5,35.3)$ \\
\hline
\end{tabular}

Note: based on reports from respondents complaining of at least one sexual problem. All prevalences are adjusted according to the age distribution of the total of sexually active men and women in this sample from Brazil. 
problems investigated were significantly associated with seeking medical help, but among women lubrication difficulty was a significant correlate of seeking medical help (odds ratio 2.66; $\mathrm{p}<0.01$ ). Having been asked by a doctor about possible sexual difficulties during a routine visit in the past three years was a significant correlate of seeking medical help for sexual problems for both men (odds ratio 4.72; $<<0.01$ ) and women (odds ratio 1.92; $\mathrm{p}<0.05$ ) in Brazil. Sexual attitudes and beliefs that were significantly associated with seeking medical help for sexual problems were: among women, thinking that a doctor should routinely ask patients about sexual problems (odds ratio 2.44; $\mathrm{p}<0.05$ ); and among men, being somewhat or very dissatisfied with their sexual function (odds ratio 3.16; $\mathrm{p}<0.05$ ) and believing that sex is an extremely or very important part of life (odds ratio 2.79; $\mathrm{p}<0.05)$.
ATtitudeg AND BELIEFg ABDUT DIAENGGIB AND TREATMENT DF GEXUAL PROBLEMB

By far the most common reason cited by men and women in Brazil for not consulting a doctor about a sexual problem was a belief that it is a normal part of aging, or being comfortable as he/she is (81.7\% of men and $85.6 \%$ of women) (Table 6). However, thinking the problem was not very serious or waiting for it to go away $(59.1 \%$ of men and $69.9 \%$ of women); feelings of discomfort or embarrassment about talking to a doctor $(52.4 \%$ of men and $60.8 \%$ of women); and thinking it was not a medical problem or that a doctor could not do much to help $(57.9 \%$ of men and $58.8 \%$ of women), were all cited by more than half of all respondents (Table 6). Lack of access to or affordability of medical care was also cited as a reason by about half of the men (54.9\%) and women (46.4\%). Few respondents in Brazil had been asked by a doctor about pos- sible sexual difficulties during a routine visit in the past 3 years $(13.6 \%$ of men and $19.8 \%$ of women) but more than three-quarters of men $(85.4 \%)$ and women $(76.9 \%)$ thought that a doctor should routinely ask patients about their sexual function.

DISCUSSIDN

The Global Study of Sexual Attitudes and Behaviors has obtained population-level data on sexual attitudes and behaviors from middle-aged and older adults in 29 countries in a manner that allows direct comparisons of the results from different countries and regions. The large, cross-national sample and the use of a common method of data collection represent two major strengths of this study. Here, we have focused specifically on the sexual activity, prevalence of sexual problems and associated help-seeking behavior among men and women in Brazil. The standardized, structured questionnaire was administered using

Table 5. Factors associated with seeking medical help for sexual problems by gender, Brazil, 2001-2002

\begin{tabular}{|c|c|c|}
\hline & Men & Women \\
\hline \multicolumn{3}{|l|}{ Age (years) } \\
\hline $40-49$ & Reference & Reference \\
\hline $50-59$ & $1.48(0.51,4.27)$ & $1.12(0.58,2.16)$ \\
\hline $60-69$ & $2.18(0.70,6.72)$ & $0.93(0.41,2.08)$ \\
\hline $70-80$ & $2.53(0.72,8.94)$ & $0.46(0.13,1.65)$ \\
\hline \multicolumn{3}{|l|}{ Education } \\
\hline Primary school or less & Reference & Reference \\
\hline Secondary/high school & $1.60(0.57,4.49)$ & $1.46(0.76,2.80)$ \\
\hline At least some college & $1.74(0.55,5.94)$ & $1.86(0.83,4.17)$ \\
\hline High/medium household income (versus low) & $1.00(0.29,3.51)$ & $2.18(1.1,4.72)^{*}$ \\
\hline \multicolumn{3}{|l|}{ Sexual problems } \\
\hline Erectile difficulties & $1.37(0.60,3.16)$ & \\
\hline Early ejaculation & $0.54(0.22,1.30)$ & \\
\hline Lack of sexual interest & $1.17(0.49,2.82)$ & $0.69(0.38,1.25)$ \\
\hline Inability to reach orgasm & & $1.00(0.56,180)$ \\
\hline Lubrication difficulties & & $2.66(1.48,4.79)^{\dagger}$ \\
\hline \multicolumn{3}{|l|}{ General sexual Attitudes } \\
\hline Have been asked by a doctor about possible sexual difficulties in a routine visit in the past three years & $4.72(1.72,12.98)^{\dagger}$ & $1.92(1.09,3.70)^{*}$ \\
\hline Think a doctor should routinely ask patients about sexual function & $0.93(0.27,3.27)$ & $2.44(1.05,5.67)^{*}$ \\
\hline Very/somewhat dissatisfied with sexual function & $3.16(1.1,9.89)^{*}$ & $1.77(0.89,3.54)$ \\
\hline Belief that decreased ability to perform sexually would significantly affect self-esteem & $1.10(0.47,2.59)$ & $0.88(0.49,1.59)$ \\
\hline Belief that sex is a extremely/very important part of overall life & $2.79(1.10,7.11)^{*}$ & $0.91(0.30,2.78)$ \\
\hline Think it is OK to use medical treatment for sexual problems & $1.08(0.35,3.33)$ & $0.71(0.31,1.63)$ \\
\hline Think that older people no longer want/have sex & $1.12(0.48,2.65)$ & $0.61(0.34,1.11)$ \\
\hline Belief in religion guiding sex & $0.79(0.33,1.90)$ & $1.06(0.60,1.86)$ \\
\hline
\end{tabular}

Note: odds ratios from logistic regression (and $95 \%$ confidence intervals). Based on reports from respondents complaining of at least one sexual problem. ${ }^{*} p<0.05 ;{ }^{\dagger} p<0.01$ 
Table 6. Attitudes, behaviors and beliefs about diagnosis of and treatment for sexual problem by gender, Brazil, 2001-2002

\begin{tabular}{|c|c|}
\hline & $\%(95 \%$ confidence interval) \\
\hline \multicolumn{2}{|l|}{ Men } \\
\hline \multicolumn{2}{|l|}{ Reasons for not consulting a doctor about the sexual problem experienced:* } \\
\hline Normal with aging/I am comfortable the way I am & $81.7(74.9,87.3)$ \\
\hline Did not think it was very serious/Waiting to see if problem goes away & $59.1(51.2,66.7)$ \\
\hline Doctor cannot do much/Do not think it is a medical problem & $57.9(50.0,65.6)$ \\
\hline Do not have a regular physician/Doctor is expensive & $54.9(46.9,62.6)$ \\
\hline Not comfortable talking to a $M D / M D$ is a close friend/MD is the wrong gender & $52.4(44.5,60.3)$ \\
\hline Doctor uneasy to talk about sex & $25.6(19.1,33.0)$ \\
\hline Have been asked by a doctor about possible sexual difficulties in a routine visit in the past three years ${ }^{\dagger}$ & $13.6(10.6,17.0)$ \\
\hline Think a doctor should routinely ask patients about their sexual function ${ }^{\dagger}$ & $85.4(81.8,88.4)$ \\
\hline \multicolumn{2}{|l|}{ Women } \\
\hline \multicolumn{2}{|l|}{ Reasons for not consulting a doctor about the sexual problem experienced:* } \\
\hline Normal with aging/I am comfortable the way I am & $85.6(79.0,90.8)$ \\
\hline Did not think it was very serious/Waiting to see if problem goes away & $69.9(62.0,77.0)$ \\
\hline Not comfortable talking to a $M D / M D$ is a close friend/MD is the wrong gender & $60.8(52.6,68.6)$ \\
\hline Doctor cannot do much/Do not think it is a medical problem & $58.8(50.6,66.7)$ \\
\hline Do not have a regular physician/Doctor is expensive & $46.4(38.3,54.6)$ \\
\hline Doctor uneasy to talk about sex & $22.2(15.9,29.6)$ \\
\hline Have been asked by a doctor about possible sexual difficulties in a routine visit in the past three years ${ }^{\dagger}$ & $19.8(16.9,22.9)$ \\
\hline Think a doctor should routinely ask patients about their sexual function ${ }^{\dagger}$ & $76.9(73.7,79.9)$ \\
\hline
\end{tabular}
distribution of the total of sexually active men and women in this sample from Brazil. MD = medical doctor.

computer-assisted telephone interviews. This method was chosen in preference to face-toface interviews to avoid causing respondents undue embarrassment when talking about private and sensitive issues, and to minimize the likelihood that they might feel obliged to give "socially desirable" answers. ${ }^{26}$

Only sexual problems that were experienced periodically or frequently (i.e. those that persisted with moderate to higher frequency) were considered to be "dysfunctions". ${ }^{27}$ This is essentially equivalent to using two sequential screening tests, and minimizes the risk of false positive responses. It is likely, therefore, that the prevalence of sexual dysfunction may be under-reported in the Global Study of Sexual Attitudes and Behaviors, in comparison with studies that used more sensitive, but less specific, methods. Published studies on the prevalence of male erectile dysfunction in Brazil have highlighted the need to consider the severity or frequency of a sexual dysfunction when comparing reports from apparently similar study samples. Two population-based surveys conducted in Brazil, one in the northeast ${ }^{13}$ and the other in the southeast, ${ }^{14}$ reported a prevalence of moderate or complete erectile dysfunction of $14.4 \%$ and $12.0 \%$, respectively, among Brazilian men aged 40 to 70 years. Likewise, in a national survey in Brazil, the prevalence of moderate or complete erectile dysfunction was $14.7 \% .{ }^{12}$ These estimates are similar to what was observed in the GSSAB Brazilian cohort, in which the overall age- standardized prevalence of erectile difficulties was $13.8 \%$ (9.8\% experienced the problem frequently or periodically).

The overall response rate in Brazil (18.4\%) was low, but the prevalence of a number of self-reported health conditions, including hypertension, diabetes and smoking in GSSAB was comparable with published values. ${ }^{28-31}$ This suggests that refusal to participate in this study was most probably due simply to an unwillingness to undergo a telephone interview and the modest response rate is therefore unlikely to have introduced a bias in the estimates of the prevalence of sexual behaviors and problems. It also appears to indicate that the study population was broadly representative of the Brazilian population. This assumption is further supported by the observation that the prevalence of erectile difficulties among men in the Brazilian cohort of the GSSAB was comparable to what has been reported in published studies, which have focused on the prevalence of moderate or severe erectile dysfunction among Brazilian men aged between 40 and 70 years. ${ }^{13,14,32}$

A diagnosis of depression was a significant correlate of a lack of sexual interest for both genders, and of erectile difficulties and early ejaculation among men in the GSSAB Brazilian cohort. A lack of sexual interest was also significantly associated with prostate disease and early ejaculation with a diagnosis of hypertension. Interestingly, none of the reported medical conditions, apart from depression, were significant correlates of sexual problems among Brazilian women in the GSSAB. Comorbidity between erectile dysfunction and depression is known to exist but the precise nature of the relationship between these conditions is not clear. ${ }^{33}$ While it is possible that the distress of erectile dysfunction may contribute to the development of depressive illness, it is also possible that depressive illness may lead to erectile difficulties. Moreover, it is important that the possible role of antidepressant treatments is considered when investigating the copresence of depression and sexual dysfunction. Sexual dysfunction is a well-recognized side effect of antidepressant therapy. However, different agents may be associated with different rates of dysfunction. ${ }^{34-36}$ Selective serotonin reuptake inhibitors (SSRIs) have been reported to be associated with particularly high rates of sexual dysfunction and, while men report higher rates of sexual side effects from SSRIs than do women, women seem to experience more severe dysfunction with these agents. ${ }^{35,37}$ A significant association between depression and erectile dysfunction among men in Brazil has been reported previously. ${ }^{12-14}$ However, the data from GSSAB indicate that depression is also associated with other male sexual problems, namely early ejaculation and a lack of sexual interest. Despite the correlation between sexual problems and depression, the relationship is most probably bi-directional, i.e. sexual problems may follow depression, while depression may be a consequence of 
sexual dysfunction. We cannot discern the causal direction in these cross-sectional data. The association between depression and sexual dysfunction warrants further investigation because depression is highly prevalent in Brazil and other Latin American countries, possibly due at least in part to social factors such as violence that are especially present in medium and large cities. ${ }^{38}$ (For logistical reasons, the Brazilian sample in GSSAB was drawn primarily from urban areas.)

The GSSAB data indicate that feeling that the problem is not severe, or not being bothered by the problem, may be deterring men and women in Brazil from discussing their sexual difficulties with their doctor. Furthermore, it appears that doctors in Brazil rarely ask patients about their sexual health during a routine consultation, even though the vast majority of men and women would appreciate this and it would appear to encourage medical help-seeking for sexual problems. Untreated sexual problems can greatly impair a patient's enjoyment of their sexual life and it is important that physicians, especially primary care physicians, ask patients about possible sexual difficulties during routine visits. ${ }^{39}$ This should result in improved sexual functioning for the patient and an enhanced physician-patient relationship and greater professional satisfaction.

Socioeconomic factors also influence patterns of help-seeking behavior for sexual problems among mature men and women in Brazil. Our findings indicate that women with a medium or high household income were significantly more likely to seek help than women from low-income households. Furthermore, a lack of access to or affordability of medical care was cited by about one-half of all respondents, both men and women, as a reason for not seeking medical help for sexual problems. A recent crosssectional study performed in Rio Grande do Sul, Brazil, showed that only $37 \%$ of the study sample had a regular doctor and that this was directly associated with income. ${ }^{40}$ The authors also found that individuals with a regular physician tended to have better access to a range of health services and they recommended encouraging people to consult with a regular doctor as a means of improving the quality of and access to healthcare services, particularly among the poorest individuals. Improving the care available to older adults with low income may be especially important, as a study of the influence of socioeconomic circumstances on health has demonstrated that, among a representative sample of the Brazilian population aged 65 years or older, lower income was associated with worse health and physical functioning, and less frequent use of medical services. ${ }^{41}$

CONCLUSIONS

We conclude that, although middleaged and elderly men and women in Brazil continue to show sexual interest and activity, a number of sexual problems are highly prevalent. Only a minority of the men and women who experience sexual difficulties seek medical help: this may be partly because they do not perceive such problems as potentially treatable medical conditions, or because they do not have access to or cannot afford medical care. The findings from GSSAB highlight the importance of encouraging greater use of the available healthcare services, including consultation with a medical doctor on matters of sexual health. This should not only enable men and women to maintain satisfactory sexual function well into their later years, but may also result in an overall improvement in the quality of healthcare, particularly among poorer individuals.
1. Giuliano F, Chevret-Measson M, Tsatsaris A, Reitz C, Murino M, Thonneau P. Prevalence of erectile dysfunction in France: results of an epidemiological survey of a representative sample of 1004 men. Eur Urol. 2002;42(4):382-9.

2. Martin-Morales A, Sanchez-Cruz JJ, Saenz de Tejada I, Rodriguez-Vela L, Jimenez-Cruz JF, Burgos-Rodriguez R. Prevalence and independent risk factors for erectile dysfunction in Spain results of the Epidemiologia de la Disfuncion Erectil Masculina Study. J Urol. 2001;166(2):569-74; discussion 574-5.

3. Blanker MH, Bosch JL, Groeneveld FP, et al. Erectile and ejaculatory dysfunction in a community-based sample of men 50 to 78 years old: prevalence, concern, and relation to sexual activity. Urology. 2001;57(4):763-8.

4. Helgason AR, Adolfsson J, Dickman P, et al. Sexual desire, erection, orgasm and ejaculatory functions and their importance to elderly Swedish men: a population-based study. Age Ageing. 1996;25(4):285-91.

5. Dunn KM, Croft PR, Hackett GI. Sexual problems: a study of the prevalence and need for care in the general population. Fam Pract. 1998;15(6):519-24.

6. Feldman HA, Goldstein I, Hatzichristou DG, Krane RJ, McKinlay JB. Impotence and its medical and psychosocial correlates: results of the Massachusetts Male Aging Study. J Urol. 1994;151(1):54-61.
7. Panser LA, Rhodes T, Girman CJ, et al. Sexual function of men ages 40 to 79 years: the Olmsted County Study of Urinary Symptoms and Health Status Among Men. J Am Geriatr Soc. 1995;43(10):1107-11.

8. Laumann EO, Paik A, Rosen RC. Sexual dysfunction in the United States: prevalence and predictors. JAMA. 1999;281(6):537-44.

9. Ansong KS, Lewis C, Jenkins P, Bell J. Epidemiology of erectile dysfunction: a community-based study in rural New York State. Ann Epidemiol. 2000;10(5):293-6.

10. Bacon CG, Mittleman MA, Kawachi I, Giovannucci E, Glasse DB, Rimm EB. Sexual function in men older than 50 years of age: results from the health professionals follow-up study. Ann Intern Med. 2003;139(3):161-8.

11. Ugarte y Romano F, Barroso AJ. Prevalencia de disfunción eréctil en México y factores de riesgo asociados. Rev Mex Urologia. 2001;61(2):63-76.

12. Moreira ED Jr, Abdo CH, Torres EB, Lisboa Lobo CF, Fittipaldi JA. Prevalence and correlates of erectile dysfunction: results of the Brazilian study of sexual behavior. Urology. 2001;58(4):583-8.

13. Moreira ED Jr, Lisboa Lobo CF, Villa M, Nicolosi A, Glasser DB. Prevalence and correlates of erectile dysfunction in Salvador, northeastern Brazil: a population-based study. Int J Impot Res. 2002;14(Suppl 2):S3-9.
14. Moreira ED Jr, Bestane WJ, Bartolo EB, Fittipaldi JA. Prevalence and determinants of erectile dysfunction in Santos, southeastern Brazil. Sao Paulo Med J. 2002;120(2):49-54.

15. Nolazco C, Bellora O, Lopez M, et al. Prevalence of sexual dysfunctions in Argentina. Int J Impot Res. 2004;16(1):69-72.

16. Osborn M, Hawton K, Gath D. Sexual dysfunction among middle aged women in the community. Br Med J (Clin Res Ed). 1988;296(6627):959-62.

17. Barlow DH, Cardozo LD, Francis RM, et al. Urogenital ageing and its effect on sexual health in older British women. $\mathrm{Br} \mathrm{J}$ Obstet Gynecol. 1997;104(1):87-91.

18. Schiavi RC, Rehman J. Sexuality and aging. Urol Clin North Am. 1995;22(4):711-26.

19. Matthias RE, Lubben JE, Atchison KA, Schweitzer SO. Sexual activity and satisfaction among very old adults: results from a community-dwelling Medicare population survey. Gerontologist. 1997;37(1):6-14

20. Gott M, Hinchliff S. How important is sex in later life? The views of older people. Soc Sci Med. 2003;56(8):1617-28.

21. Laumann EO, Nicolosi A, Glasser DB, et al. Sexual problems among women and men aged 40 to $80 \mathrm{y}$ : prevalence and correlates identified in the Global Study of Sexual Attitudes and Behaviors. Int J Impot Res. 2005;17(1):39-57. 
22. Nicolosi A, Laumann EO, Glasser DB, et al. Sexual behaviour and sexual dysfunctions after age 40: the global study of sexual attitudes and behaviors. Urology. 2004;64(5):991-7.

23. Moreira ED Jr, Brock G, Glasser DB, et al. Help-seeking behaviour for sexual problems: the global study of sexual attitudes and behaviors. Int J Clin Pract. 2005;59(1):6-16.

24. Instituto Brasileiro de Geografia e Estatística. Pesquisa de orçamentos familiares - POF 2002-2003. Disponível em URL: http://www.ibge.gov.br/home/estatistica/populacao/condicaodevida/pof/2002/default.shtm. Acessado em: 2005 (Aug 19).

25. Gardner MJ, Altman DG. Confidence intervals rather than $P$ values: estimation rather than hypothesis testing. Br Med J (Clin Res. Ed). 1986;292(6522):746-50.

26. Analysis of sexual behaviour in France (ACSF). A comparison between two modes of investigation: telephone survey and faceto-face survey. ASCF principal investigators and their associates. AIDS. 1992;6(3):315-23.

27. Moynihan R. The making of a disease: female sexual dysfunction. BMJ. 2003;326(7379):45-7.

28. Lima-Costa MF, Barreto SM, Uchoa E, Firmo JO, Vidigal PG, Guerra HL. The Bambui Health and Aging Study (BHAS): prevalence of risk factors and use of preventive health care services. Rev Panam Salud Publica. 2001;9(4):219-27.

29. Guimaraes AC. Hypertension in Brazil. J Hum Hypertens. 2002;16(Suppl 1):S7-S10.

30. Torquato MT, Montenegro Junior RM, Viana LA, et al. Prevalence of diabetes mellitus and impaired glucose tolerance in the urban population aged 30-69 years in Ribeirão Preto (São Paulo), Brazil. Sao Paulo Med J. 2003;121(6):224-30.
31. Ala L, Gill G, Gurgel R, Cuevas L. Evidence for affluence-related hypertension in urban Brazil. J Hum Hypertens. 2004;18(11)775-9.

32. Nicolosi A, Moreira ED Jr, Shirai M, Bin Mohd Tambi MI, Glasser DB. Epidemiology of erectile dysfunction in four countries: cross-national study of the prevalence and correlates of erectile dysfunction. Urology. 2003;61(1):201-6.

33. Seidman SN. Exploring the relationship between depression and erectile dysfunction in aging men. J Clin Psychiatry. 2002;63(Suppl 5):5-12; discussion 23-5.

34. Gregorian RS, Golden KA, Bahce A, Goodman C, Kwong WJ, Khan ZM. Antidepressant-induced sexual dysfunction. Ann Pharmacother. 2002;36(10):1577-89.

35. Clayton AH, Pradko JF, Croft HA, et al. Prevalence of sexual dysfunction among newer antidepressants. J Clin Psychiatry. 2002;63(4):357-66

36. Montgomery SA, Baldwin DS, Riley A. Antidepressant medications: a review of the evidence for drug-induced sexual dysfunction. J Affect Disord. 2002;69(1-3):119-40.

37. Hensley PL, Nurnberg HG. SSRI sexual dysfunction: a female perspective. J Sex Marital Ther. 2002;28(Suppl 1):143-53.

38. Jorge MR. Depression in Brazil and other Latin American countries. Seishin Shinkeigaku Zasshi. 2003;105(1):9-16.

39. Sadovsky R. Integrating erectile dysfunction treatment into primary care practice. Am J Med. 2000;109(Suppl 9A):22S-8S; discussion 29S-30S

40. Mendoza-Sassi R, Béria JU. Prevalence of having a regular doctor, associated factors, and the effect on health services utilization: a population-based study in Southern Brazil. Cad Saúde Pública. 2003;19(5):1257-66
41. Lima-Costa MF, Barreto S, Giatti L, Uchôa E. Desigualdade social e saúde entre idosos brasileiros: um estudo baseado na Pesquisa Nacional por Amostra de Domićlíios. [Socioeconomic circumstances and health among the brazilian elderly: a study using data from a National Household Survey]. Cad Saúde Pública. 2003;19(3):745-57.

Acknowledgement: The authors acknowledge the contribution of their colleagues on the study's international advisory board: Gerald Brock (Canada), Jacques Buvat (France), Uwe Hartmann (Germany), Sae-Chul Kim (Korea), Rosie King (Australia), Edward Laumann (USA), Bernard Levinson (South Africa), Ken Marumo (Japan), Alfredo Nicolosi (ltaly) and Ferruh Simsek (Turkey).

Sources of funding: The Global Study of Sexual Attitudes and Behaviors was funded by Pfizer, Inc.

Conflicts of interest: Edson Duarte Moreira Junior is a consultant for Pfizer, Inc.; Dale Glasser is an employee of Pfizer, Inc. and owns Pfizer stock; Dianilson Barbosa dos Santos has no conflict of interest; Clive Gingell is a consultant for Pfizer, Inc.

Date of first submission: December 15,2004

Last received: August 15, 2005

Accepted: August 19, 2005

\section{AUTHOR INFDRMATIDN}

Edson Duarte Moreira Junior, MD, PhD. Centro de Pesquisa Gonçalo Moniz, Fundação Oswaldo Cruz, and scientific directorate of Hospital São Rafael, Salvador, Bahia, Brazil.

Dale Glasser, MD. Pfizer Inc, New York, United States of America.

Dianilson Barbosa dos Santos, MSc. Centro de Pesquisa Gonçalo Moniz, Fundação Oswaldo Cruz and scientific directorate of Hospital São Rafael, Salvador, Bahia, Brazil.

Clive Gingell, FRCS. Bristol Urological Institute, Southmead Hospital, Bristol, England, for the Global Study of Sexual Attitudes and Behaviors (GSSAB) Investigators' Group.

\section{Address for correspondence:}

Edson Duarte Moreira Junior

Fundação Oswaldo Cruz - Departamento de Epidemiologia e Bioestatística

Rua Waldemar Falcão, 121

Salvador (BA) - Brasil - CEP 40295-00

Tel. 1+55 71) 356-8781 Ramal 243

Fax (+55 71) 356-2155

E-mail: edson@cpqgm.fiocruz.br
Prevalência de problemas sexuais e de comportamentos relacionados à busca de ajuda para estes problemas em adultos no Brasil: resultados do estudo global de atitudes e comportamentos sexuais

CONTEXTO E OBJETIVO: A prevalência e os fatores correlatos de desordens sexuais masculinas como disfunção erétil e ejaculação precoce têm sido estudados em muitos países, entretanto, bem menos investigações se ocuparam especificamente dos problemas sexuais femininos. Além disso, relativamente pouco se sabe sobre a freqüência usual da atividade sexual e sobre como indivíduos mais velhos tentam lidar com seus problemas sexuais. O objetivo deste estudo foi estudar a atividade sexual, a prevalência de problemas sexuais e os comportamentos de busca de ajuda relacionados a esses problemas, entre homens e mulheres de meia-idade e mais velhos no Brasil.

TIPO DE ESTUDO: Inquérito populacional realizado pela Faculdade Oswaldo Cruz. Pesquisa por telefone (discagem aleatória) conduzida no Brasil em 2001 e 2002.

MÉTODOS: As entrevistas foram baseadas num questionário padronizado, incluindo informações demográficas, saúde em geral, e comportamentos, atitudes e crenças sexuais. Um total de 1.199 indivíduos no Brasil (471 homens e 728 mulheres) de 40 a 80 anos completou o inquérito.

RESULTADOS: Ao todo, 92,6\% dos homens e 58,3\% das mulheres referiram alguma atividade sexual no ano que precedeu a entrevista, e mais da metade dos homens e mulheres reportaram atividade sexual mais de uma vez uma semana. Ejaculação precoce $(30,3 \%)$ foi o problema sexual masculino mais comum, seguido por incapacidade de alcançar o orgasmo $(14,0 \%)$, dificuldades de ereção $(13,1 \%)$ e falta de interesse sexual $(11,2 \%)$. Os problemas sexuais relatados mais freqüentemente por mulheres foram dificuldades de lubrificação $(23,4 \%)$ e falta de interesse sexual $(22,7 \%)$. Depressão foi correlacionada significativamente com problemas sexuais nos homens e nas mulheres. Mais mulheres do que homens tinham procurado a ajuda de um profissional de saúde para seu problema(s) sexual(is).

CONCLUSÕES: Os achados do GSSAB destacam a importância de encorajar o maior uso dos serviços de saúde disponíveis, incluindo consultas médicas sobre queixas ligadas à saúde sexual. Isso deverá não somente possibilitar que homens e mulheres mantenham uma função sexual satisfatória até idades mais avançadas, mas também poderá resultar numa melhora geral da qualidade da assistência à saúde.

PALAVRAS-CHAVE: Epidemiologia. Levantamentos epidemiológicos. Disfunção erétil. Prevalência. Sexualidade. 